\title{
FILOSOFÍA, RAZONABILIDAD Y PENSAMIENTO COMPLEJO
}

\author{
Tomás Miranda Alonso \\ Universidad de Castilla-La Mancha
}

\section{Una ola nos invade}

Una ola invade las cavernas en las que nos encontramos los actuales prisioneros: la ola de la misología, el odio a la razón. Nunca se ha hablado tanto como en nuestros días sobre la necesidad del diálogo y de la argumentación para resolver racionalmente los problemas que surgen en la convivencia de los seres humanos. Sin embargo, es la razón de la sinrazón, como diría D. Quijote, la que parece regir las relaciones que se dan entre los nuevos encadenados de la cueva platónica. Basta abrir el periódico o la televisión para observar que aún sigue siendo la guerra el medio utilizado por muchos pueblos para «resolver» sus conflictos, y que fanatismos de todo tipo siguen Ilevando a mucha gente a utilizar el terror más despiadado para conseguir nada, sólo la muerte, la destrucción y el dolor. Se trata del mismo dolor que nos debe producir el saber que una gran cantidad de habitantes de nuestro mundo está muriendo literalmente de hambre porque el sistema económico vigente produce un incremento cada vez mayor de las desigualdades en la distribución de la riqueza mundial, y condena a la mayor parte de la población a vivir por debajo del umbral de la pobreza. Es también el mismo dolor que nos produce saber que el genocidio sigue siendo la herramienta utilizada para eliminar al otro, al diferente, y que las mujeres continúan siendo víctimas de la violencia de género. Y por si esto fuera poco, surgen países y alianzas entre algunos de ellos, los cuales se autoproclaman garantes de la «racionalidad» y del «orden» mundial, y presentan como racional cualquier decisión que ellos adopten para defender los intereses estratégicos, económicos y políticos de determinados grupos dominantes y de presión. 
Y los misólogos, abundantes en nuestras cavernas, utilizan el engaño, la mentira, la violencia y el poder para «justificar» sus puntos de vista, llegando incluso a pretender amordazar la boca de los disidentes; y se invierte gran cantidad de recursos económicos en la propaganda, que es la empresa que en las democracias tiene como función la desinformación, y que se corresponde con la censura existente en los regímenes totalitarios, e incluso es bastante más eficaz que ésta ya que resulta difícil darse cuenta del cinismo de unos medios de (des)información que se presentan como libres pero que, como dice $\mathrm{N}$. Chomsky, demasiadas veces se dedican a negar lo que es obvio. También son numerosos en nuestras cavernas los filótopos, es decir, los amantes de repetir lugares comunes y frases hechas por los nuevos dictadores de la moda y del pensamiento políticamente correcto. Del mismo modo que la sociedad nos ofrece electrodomésticos y prótesis para hacernos la vida más cómoda, nos ofrece también «envasados al vacío» los pensamientos que debemos tener, evitándonos así el esfuerzo que supone el tener que pensar por nosotros mismos. Hay una lucha encarnizada por controlar los medios de comunicación, ya que constituyen auténticas factorías en las que se produce y desde las que se transmite la opinión que ha de ser consumida por los prisioneros de unas cavernas donde la realidad es construida también mediáticamente. Como dice A. Ponzio, «sólo en la actualidad resulta claro que en cualquier forma social la realización, la organización y la reproducción del poder se verifica a través del control de las estructuras de comunicación. En la fase actual del sistema capitalista resulta evidente que el dominio no depende del hecho de poseer cosas, sino de poseer el control de los medios de comunicación, el control del intercambio en el nivel del mercado y de producción» ${ }^{1}$. No son los argumentos basados en razones los medios que los habitantes de esta caverna, cada vez más globalizada, utilizan para llegar a acuerdos válidos y aceptables intersubjetivamente, y formar, de este modo, opiniones razonables, aunque, por supuesto, provisionales y falibles, sino la mentira, que, a fuerza de repetirse, se acepta como verdadera.

En nuestras cavernas son legión los que, como diría Kant², Ilevados por la pereza siguen en su culpable minoría de edad y son incapaces de pensar por sí mismos: la comodidad, la prisa, el ruido, el gusto por la superficialidad, son factores que influyen en la configuración de un tipo frecuente de individuo que padece una grave anemia argumentativa y que está dispuesto a aceptar como válido cualquier razonamiento que se le presente, aduciendo el tópico relativista de que todas las opiniones tienen el mismo valor.

En estas circunstancias hay que apostar más que nunca por la filo-logía, es decir, por el compromiso apasionado en la búsqueda de razones, y es urgente que se produzca un esfuerzo colectivo por pensar el complejo mundo en el

${ }^{1}$ PONZIO A., El juego del comunicar, Valencia, Ed. Episteme, 1995, p. 29.

${ }^{2}$ KANT E., “¿Qué es la Ilustración?”, en Filosofía de la Historia, Madrid, F.C.E., 1985. 
que los seres humanos vivimos actualmente y construir ideas capaces de orientar nuestra acción y desde las que se puedan articular discursos que permitan someter a crítica el único pensamiento que se nos pretende imponer como racional. Esta ha sido la función de la filosofía en todos los tiempos, la de potenciar un razonamiento-discurso (logos) capaz de pensar la complejidad, y para ello tal discurso ha de ser construido en un diálogo interdisciplinar y abierto a la totalidad de los que quieran participar en él, con la única condición de no usar en la presentación de sus puntos de vista más fuerza que las razones con las que defienden sus argumentos. Una actividad tal -y la filosofía es, sobre todo, una actividad- es capaz de criticar la pretendida racionalidad de los discursos dominantes en cada sociedad y momento determinado. Pero esa crítica a la racionalidad vigente hay que hacerla desde la misma racionalidad, pues ésta constituye el límite lingüístico del que no nos podemos salir cuando razonamos. Como dice K. O. Apel, la argumentación mediante la que apoyamos un pensamiento con pretensión de validez intersubjetiva es irrebasable en filosofía y, por ello, quienes pretenden hacer una crítica total de la razón incurren en una contradicción performativa de naturaleza pragmática ${ }^{3}$.

En esta época, en que tenemos acceso a una cantidad ingente de información, sigue siendo necesario cultivar el pensamiento, y el objetivo de toda educación -que es un proceso de formación que no termina hasta la muerte- no puede ser otro que el de aprender a pensar. Caminamos hacia lo que se ha llamado la Sociedad del Conocimiento, y cada vez son más numerosos los medios materiales y humanos que se dedican a potenciar el conocimiento de la realidad para poder manipularla y controlarla. Las ciencias nos proporcionan verdades particulares sobre los fenómenos de nuestra experiencia y su cultivo responde, en principio, a la curiosidad natural del ser humano y a su deseo de convertir el medio en que vive en un hogar habitable por él, es decir, en un mundo. Pero, como dice Hannah Arendt, conocer no es lo mismo que pensar, pues el conocimiento busca verdades, mientras que la actividad de pensar tiene como finalidad buscar o crear sentido. Las verdades a las que podemos llegar con el método científico no son capaces de saciar la necesidad de saber que tiene el hombre, el cual no se conforma con el mero conocimiento de una parte de la realidad, la que se reduce a relaciones cuantitativas y cognoscible con el método hipotético-deductivo. Además del conocer, que nos presenta verdades formales y empíricas, es necesario el pensar, es decir, el esfuerzo de la razón compartida por buscar y dar sentido a la experiencia humana. El pensamiento es como el arco que arroja continuamente el dardo de la pregunta a la totalidad de lo real, sin detenerse ante el imperio de las apariencias sensibles ni del propio sentido común. Pero el pensar y el conocer no son dos actividades rivales, ya que la necesidad que tenemos los humanos de hacernos constantemente preguntas sobre el sentido y la complejidad de nuestra existencia posibilita, a

${ }^{3}$ APEL K. O., El desafío de la crítica total a la razón, Valencia , Episteme, 1994. 
su vez, la misma actividad cognoscitiva y científica. Por ello, dice H. Arendt, la razón pensante, la razón que no para de hacer preguntas que carecen de una respuesta capaz de tranquilizar nuestro espíritu, es condición a priori del conocimiento: "Al trazar una línea divisoria entre verdad y significado, entre conocer y pensar, e insistir en su importancia, no pretendo negar la conexión entre la búsqueda de significado que Ileva a cabo el pensamiento y la búsqueda de la verdad propia del conocimiento. Al formular la pregunta del significado, que carece de respuesta, los hombres se muestran como seres interrogantes. Detrás de todas las preguntas cognitivas para las que los hombres encuentran respuesta acechan las que no la tienen, que parecen completamente ociosas y como tales han sido siempre denunciadas. Es más que probable que si los hombres perdiesen alguna vez el ansia de significado que llamamos pensar y dejasen de plantear preguntas sin respuesta, no sólo dejarían de ser capaces de crear esos objetos-pensamiento llamados obras de arte, sino que tampoco podrían plantear todas las preguntas sin respuesta en las que se apoya toda civilización. En este sentido la razón es la condición a priori de la cognición» ${ }^{4}$. Este texto debería ser leído y meditado por muchos administradores y planificadores de las universidades, que a la hora de asignar y repartir recursos parece que se dejan llevar por una cierta desconsideración, por supuesto tácita, hacia aquellos estudios o grupos de investigación cuyo objetivo principal no es el de producir conocimientos utilizables directamente en procesos productivos científico-técnicos. Su cortedad de vista les hace ignorar que sin pensamiento no hay conocimiento, en el sentido que $\mathrm{H}$. Arendt le da a estos términos.

\section{Pero la racionalidad, como el ser, se dice de varias modos}

Si el objetivo del proceso educativo es llegar a pensar críticamente, entonces las comunidades educativas -y no me refiero sólo a las que pertenecen a la red de lo que se entiende por educación formal- deben ser auténticos laboratorios de racionalidad, ya que el ejercicio de ésta, como dice Kant, tiene la virtud de formar ciudadanos autónomos, libres, responsables y solidarios. Pero, como todos sabemos, los términos «razón» y «racionalidad» no son unívocos y se han usado de diferentes maneras, siendo necesario, por tanto, la actividad filosófica de someter a crítica estas categorías, pues bien pudiera ocurrir que por «racional» se entendiera un sistema de conocimientos, creencias y acciones encaminado tan sólo a perpetuar una forma de organización social que sólo responde a los intereses de una minoría de grupos, incapaz, por otro lado, de permitir el desarrollo integral de todas las personas.

En Occidente se ha entendido frecuentemente la Razón como una fuerza independiente de nuestra corporalidad (razón desencarnada), ajena, por tanto, a nuestra dimensión sentimental y pasional. Por ello, se ha presentado, a veces,

\footnotetext{
${ }^{4}$ ARENDT H., La vida del espíritu, Madrid, Centro de estudios constitucionales, 1984, p. 80.
} 
a lo largo de la historia de la filosofía una lógica de la razón enfrentada a la lógica del corazón, y una realidad que piensa, contrapuesta a una realidad corporal. Pero estos planteamientos ignoran que es precisamente a partir de nuestra experiencia corporal en relación con el medio como vamos construyendo núcleos significativos, que, a su vez, proyectamos para construir significados aparentemente más alejados de nuestra experiencia inmediata -proyecciones metafóricas ${ }^{5}$. Los conceptos más abstractos, como los filosóficos e incluso los científicos, se originan en la interacción de nuestro cuerpo con el mundo, en nuestra experiencia corporal cotidiana con las cosas, gracias a la función cognitiva, y no meramente retórica que tiene la metáfora, sin la cual no podríamos pensar $^{6}$. Es ella la que, como dice H. Arendt, permite al espíritu estar vinculado constantemente con nuestra experiencia corporal y cotidiana; no hay dos mundos, uno sensible y otro no sensorial, porque la metáfora nos permite unirlos, es decir, «transferir» («meta-pherein») nuestras experiencias sensoriales al mundo de nuestros pensamientos más abstractos, de los que constituyen la carne (proyección metafórica): «Las analogías, metáforas y emblemas son los hilos a través de los cuales el espíritu se vincula al mundo, aun cuando por distracción pierda el contacto directo con él, y garantizan la unidad de la experiencia humana. Además, en el interior del proceso del pensamiento, sirven como modelos que nos ofrecen un punto de apoyo para que no tropecemos a ciegas con experiencias que nuestros sentidos, en su relativa certeza, no nos pueden ayudar a atravesar. El simple hecho de que el espíritu sea capaz de encontrar tales analogías, que el mundo de los fenómenos nos recuerde cosas no aparentes, se puede considerar como una especia de "prueba" de que cuerpo y espíritu, pensamiento y experiencia sensorial, lo visible y lo invisible, van unidos, están, por decirlo así, "hechos" el uno para el otro» ${ }^{7}$.

La propia filosofía occidental ha utilizado metáforas para acuñar el significado del término «razón» ${ }^{8}$. En ocasiones hemos entendido la Razón como un Padre Común Estricto que promulga órdenes morales universales, que han de ser

\footnotetext{
${ }^{5}$ MIRANDA T., «El cuerpo, fuente de significado», en C. BLANCO, A. MIÑAMBRES y T. MIRANDA (coord.), Pensando el cuerpo, pensando desde un cuerpo, Albacete, Popular Libros, 2002, p. 73-83.

${ }^{6}$ DE BUSTOS E., La metáfora. Ensayos transdisciplinares, Madrid, FCE/UNED, 2000. En este libro se defiende la tesis de que la metáfora es un mecanismo básico en la asimilación de la experiencia, en la constitución de los conceptos y en la articulación del conocimiento, tanto común como científico. En esta línea, G. LAKOFF y M. JOHNSON en Metáforas de la vida cotidiana (Cátedra, Madrid, 1986) defienden que las metáforas no son sólo un recurso de embellecimiento del lenguaje, sino una parte muy importante del lenguaje cotidiano con el que percibimos y pensamos la realidad, hasta el extremo de que la familiaridad que se tiene con ellas impide, con frecuencia, que sean percibidas como tales.

${ }^{7}$ ARENDT H., op. cit., p. 131.

${ }^{8}$ LAKOFF G. - JOHNSON M., Philosophy in the Flesh. The embodied mind and its challenge to Western Thought, New York, Basic Books, 1999. Los autores sacan a la luz las metáforas sobre las que se ha construido la filosofía occidental, la cual, paradójicamente, ha entendido la razón como una entidad desencarnada.
} 
obedecidas por todas las criaturas racionales. En la tradición kantiana sólo será buena moralmente aquella voluntad que, como el hijo obediente, se deje llevar por las órdenes paternas, venciendo la antagónica atracción diabólica que procede del deseo y del sentimiento. Relacionada con esta metáfora, la Razón también ha sido entendida frecuentemente como una supraestructura de legalidad universal y absoluta, que trata de imponerse como una Fuerza -la fuerza de la razón-, rigiendo nuestra manera de pensar y de actuar. Esta razón es la que regula el orden que hay en el universo, y está presente también en el ser humano o, como dice Platón, en la parte racional del alma humana, que tiene como funciones propias la adquisición del conocimiento intelectual y el control y dominio de los «caballos» irracionales del hombre. Y es que la Razón ha sido entendida también como Luz, que ilumina unos objetos especiales -las ideas- que pueden ser alcanzados por los videntes que tengan la suficiente inteligencia, o agudeza visual. Esta luz de la razón es la que ha de guiar también el camino que todo hombre justo ha de recorrer en su vida. Obsérvese que esta metáfora obliga a prescindir del mundo inconsciente en la construcción de una teoría de la racionalidad. Será la posesión de ésta la que distinguirá específicamente al ser humano del resto de los animales, e incluso permitirá al primero ser semejante a los dioses, pues la Razón se considerará de naturaleza divina y expresión de la voluntad de Dios, la cual exige, por tanto, la obediencia de los seres racionales.

Este juego de metáforas contribuye a entender la Razón como un orden legiforme universal y absoluto, independiente de las contingencias históricas y locales de los hombres (razón descontextualizada). Y con excesiva frecuencia, quien cree haber conseguido ese orden intenta imponerlo a los demás por la fuerza, con la excusa de trabajar por un mundo mejor y con el convencimiento de ser llamado a una tarea «mesiánica». Bajo el velo de la racionalidad se han justificado ideológicamente los intereses de opresión y de dominio de unos grupos o pueblos frente a otros. Y, como en las películas de vaqueros, los «buenos» deben imponer su modo de vida -que, por supuesto, es verdadero, bueno y bello, o sea, «racional»- a los demás, utilizando las armas si fuera necesario. Se trata, pues, de una racionalidad que pretende reducir al Otro -al extranjero, al pobre, a la viuda- a mi propio Yo, o eliminarlo (razón reductivoeliminatoria $)^{9}$. El etnocentrismo, la xenofobia y las nuevas formas de cruzadas o guerras santas son sus frutos.

\footnotetext{
${ }^{9}$ Pero, como dice Levinas, el Otro, el cual se me presenta como un rostro desnudo, expresa en su gesto, fundador de todo significado, la imposibilidad de ser reducido y asimilado a la totalidad, a mi mismidad, y me exige una relación lingüística en la que se respete su trascendencia. Quizá sea por esto por lo que los presos iraquíes torturados por soldados estadounidenses aparecen con el rostro tapado o desnudos en grupo, que es una forma de borrar cualquier indicio de individuación, al reducir el cuerpo del otro a mera carne informe. El lenguaje instaura una relación con el Otro irreductible a la relación sujeto-objeto; la obra del lenguaje consiste en entrar en relación con una desnudez desligada de toda forma, pero que tiene un sentido por sí misma, que significa antes de que proyectemos luz sobre ella. LEVINAS E., Totalidad e infinito, Salamanca, Ed. Sígueme, 1999.
} 
Como dice A. Damasio ${ }^{10}$, la equivocación de Descartes consistió en pensar que la mente humana es una realidad distinta del cuerpo y que, por tanto, puede funcionar independientemente de éste. Las investigaciones actuales en neurología ponen de manifiesto que la mente emerge de la actividad de los circuitos neuronales, sin la que no es posible actividad cognoscitiva alguna. Por tanto, no podemos hoy seguir manteniendo la idea de una razón fría, que piensa y razona sin tener en cuenta los sentimientos y las pasiones del sujeto viviente, que es independiente de su corporalidad, de su pertenencia a un género, a una sociedad y a una cultura. Nuestras actividades mentales son producidas por un cuerpo -razón encarnada-, del que no podemos prescindir para entenderlas, y nuestro cuerpo es, a su vez, el de un organismo que se relaciona con el medio en que vive, siempre desde un contexto socio-cultural determinado. No podemos entender, pues, la razón humana como una realidad descorporeizada, universal y trascendente ante cuya mirada las cosas se presentan de una manera absolutamente objetiva, como si del ojo divino se tratara: «La razón no es de ningún modo, un rasgo trascendente del universo o de una mente desencarnada. Al contrario, ella está configurada fundamentalmente por las peculiaridades de nuestros cuerpos humanos, por los notables detalles de la estructura neuronal de nuestros cerebros y por la especificidad de nuestro cotidiano funcionamiento en el mundo» ${ }^{11}$. Es nuestro cuerpo quien produce los conceptos al interrelacionarse con el medio que le rodea, convirtiendo éste en mundo. Los sistemas categoriales con los que entendemos la realidad dependen de la estructura de nuestro cuerpo, especialmente de nuestro cerebro, del medio físico que nos rodea y del medio cultural en que nacemos y nos desarrollamos. No hay que acudir a un abstracto sujeto trascendental para explicar la existencia de universales racionales, ya que éstos hunden sus raíces en unos cuerpos que tienen en parte una estructura biogenética innata y común a la especie y se relacionan con un medio físico que también es parcialmente igual para todos los hombres. Nuestra actividad mental es producida por un cuerpo que se relaciona con el medio, que tiene experiencia, pero una experiencia que está mediada por la cultura y, en definitiva, por el lenguaje: la razón surge del cuerpo, y el cuerpo es configurado, a su vez, por la razón.

La razón pura, fría, algorítmica y desencarnada debe ser sustituida por una razón sentimental y apasionada, que no prescinde de las emociones, una razón hecha carne y de carne. Se trata de una razón que, gracias al lenguaje, posibilita que hombres y mujeres seamos cuerpos capaces de trascendernos, de abrirnos unos a otros, de construir juntos significados, de buscar las razones de los acontecimientos y de ofrecer justificación de nuestras elecciones. Por ello, ha de abandonarse una concepción objetivista del conocimiento que defienda que la realidad tiene una estructura racional independiente del sujeto cognoscente, el cual, gracias a su entendimiento, puede captarla y expresarla después en el lenguaje. Gran parte de nuestro razonamiento cotidiano, científico y lite-

\footnotetext{
${ }^{10}$ DAMASIO A., El error de Descartes, Barcelona, Crítica, 1996.
}

${ }^{11}$ LAKOFF G. - JOHNSON M., op. cit. p. 4. 
rario se basa en la utilización de sistemas metafóricos, y, por ello, no es posible establecer una clara distinción objetivista entre el significado literal y el significado figurado ${ }^{12}$. Es difícil mantener la idea de una literalidad entendida como correspondencia directa entre los nombres y las $\operatorname{cosas}^{13}$.

La razón también ha sido entendida como un instrumento de manipulación y dominio de la naturaleza y de las relaciones sociales, que reduce la realidad a número y medida. Ella se ve reducida a mero instrumento -razón instrumentalque tiene como función la de conseguir unos fines que ella no ha propuesto: «la razón misma se ha convertido en simple medio auxiliar del aparato económico omnicomprensivo. La razón sirve como instrumento universal, útil para la fabricación de todos los demás, rígidamente orientado a su función, fatal como el trabajo exactamente calculado en la producción material, cuyo resultado para el hombre se sustrae a todo cálculo. Finalmente se ha cumplido su vieja ambición de ser puro órgano de fines» ${ }^{14}$. Se ha entendido la razón como un instrumento de producción de objetos -razón fabril- y de organización social basada en la búsqueda de la rentabilidad económica como valor supremo -razón economicista-, y se la ha divinizado hasta el punto de sacrificar en su honor, en ocasiones, servicios públicos de merecido prestigio -como la educación y la sanidad- con la excusa de su falta de rentabilidad. Muchas veces se han presentado como exigencias de la razón los intereses de aquellos que la monopolizan: razón servil.

\section{La filosofía como pensamiento abierto a la complejidad}

Sigo manteniendo la ilusión ilustrada de la necesidad de apostar por la razón para construir formas de vida en común más justas, en donde todos los seres humanos puedan vivir conforme a la dignidad que les corresponde como tales, y pienso que las escuelas deberían ser auténticos laboratorios de racionalidad, en donde maestros y estudiantes aprendieran a leer y pensar la realidad, y en

\footnotetext{
${ }^{12}$ En resumen, las tesis centrales de la teoría del conocimiento que estamos criticando son: a) El mundo está formado por objetos, que mantienen unas determinadas relaciones independientes de nuestra comprensión; b) esos objetos, en la medida en que tienen propiedades comunes, se agrupan formando conjuntos definidos, con los que se corresponden nuestros conceptos; c) nuestro conocimiento es verdadero en la medida en que refleje con más fidelidad la estructura del mundo; y d) nuestro lenguaje permite describir la realidad objetiva en la medida en que utilicemos conceptos que se correspondan con los objetos del mundo, con sus propiedades y con sus relaciones de un modo literal. El error de esta teoría consiste en ignorar que entre los símbolos y el mundo se produce la comprensión, que es un modo de ser-en-el-mundo: es a través de nuestros esquemas corporales como tenemos experiencia del mundo, y son estos esquemas los que nos permiten proyectar el conocimiento que tenemos de un ámbito de la realidad para entender otros ámbitos distintos -proyecciones metafóricas-. Para profundizar en estas cuestiones referentes a la semántica de la comprensión vs. semántica objetivista puede consultarse a JOHNSON M., El cuerpo en la mente, Madrid, Debate, 1991.

${ }^{13}$ LYNCH E., Dioniso dormido sobre un tigre, Barcelona, Destino, 1993.

${ }^{14}$ HORKHEIMER M. - ADORNO T., Dialéctica de la Ilustración, Madrid, Trotta, 1997, p. 83.
} 
donde se potenciara el desarrollo de una imaginación creativa capaz de construir nuevos significados que permitieran orientar la acción. Pero para no caer en una ingenuidad de corte idealista o intelectualista debemos ser cautelosos y plantearnos, al menos, algunas preguntas de carácter crítico: ¿Qué concepto de racionalidad ha de utilizar un proyecto educativo que pretenda ser realmente transformador de la realidad y de las condiciones que impiden que los hombres y las mujeres se liberen de las cadenas que les imposibilitan realizarse plenamente como seres humanos?, ¿qué racionalidad hay que cultivar, cuyo ejercicio facilite la emancipación de aquellos poderes que impiden a los seres humanos ser autónomos y dueños de su historia?, ¿cómo articular una crítica a la razón "globalmente» dominante, que genera y reproduce excluidos, y qué tipo de racionalidad potenciar capaz de permitir la liberación de las propias víctimas? ${ }^{15}$.

La Razón es de naturaleza dialógica. Pensar consiste en crear, interpretar y procesar significados. Pero estos significados nos los encontramos ya dados en el lenguaje que recibimos o, mejor dicho, en los diferentes lenguajes y relatos que recibimos y que constituyen nuestra compleja y «mestiza» identidad. No somos conciencias aisladas que nos relacionamos individual, directa y unidireccionalmente con un mundo exterior a nosotros, sino que lo hacemos desde una comunidad de hablantes, y la realidad se nos presenta siempre mediada lingüísticamente. Por tanto, todo conocimiento es un caminar a través de un lenguaje, que siempre es compartido, es decir, un diá-logos. El pensamiento consiste, pues, en un diálogo: con la propia tradición cultural, con otras tradiciones, con los clásicos, con los contemporáneos... y con nosotros mismos. Si el sujeto de conocimiento es siempre una comunidad que dialoga, entonces el proceso educativo se tiene que dar en comunidades de investigación en donde por medio del diálogo se aprenda a pensar cooperativamente y en donde el otro sea considerado no como una amenaza a mi identidad, sino como la condición de posibilidad del propio ejercicio de la razonabilidad. Prefiero usar este término, en vez de «racionalidad», para evitar el carácter fuerte, monológico y excluyente con que con frecuencia se ha usado esta segunda palabra. La persona razonable es aquella que es consciente de la complejidad de la realidad y, por ello, se ejercita en el ejercicio de un pensamiento complejo, no dogmático, consciente de su propia falibilidad, abierto a la crítica del otro, y que se deja cuestionar por las voces y las críticas de los otros, ante quienes está

\footnotetext{
${ }^{15}$ El planteamiento de una filosofía liberadora que critica desde las víctimas del sistema mundo la totalidad excluyente que se presenta como racional se puede ver en DUSSEL E., Ética de la liberación. En la edad de la liberación y de la exclusión. Madrid, Trotta, 1998 (2ª ed.). Esta Ética desea dar cuenta, en primer lugar, de la dialéctica contradictoria que se establece en un proceso de globalización en que se encuentra apresada la periferia mundial, por un lado, en cuanto sometida a un proceso de modernización dentro de la globalización formal del capital -racionalidad-, pero que, por otra parte, produce la exclusión material y discursivo formal creciente de ese pretendido proceso civilizador; y, en segundo lugar, pretende, a su vez, pensar y justificar la liberación de las cadenas que mantienen en la pobreza y en la incapacidad de reproducir la vida a la mayoría de la población mundial. (p. 17)
} 
en una constante actitud de escucha. Este tipo de pensamiento es, a la vez, crítico y creativo, consciente de sus propios supuestos e implicaciones, así como de las razones y evidencias en las que se apoyan sus conclusiones, y capaz de imaginar nuevas formas de mirar y relacionar los elementos integrantes de la experiencia. Si nuestro pensamiento es de naturaleza narrativa, entonces la educación para pensar la complejidad debe potenciar el desarrollo de una racionalidad imaginativa, capaz de crear nuevos esquemas relacionales -relatos- que ayuden a los hombres y a las mujeres en su praxis liberadora. Como dice $M$. Johnson, una imaginación moral crítica debería estar a la base de nuestra autocomprensión y de nuestras deliberaciones cuando pretendemos, por ejemplo, resolver los dilemas morales que se nos presentan en el curso de nuestra vida: "Lo que más necesitamos en tales casos es imaginación moral en sus variadas manifestaciones como un medio tanto de conocimiento como de crítica. Necesitamos autoconocimiento de la estructura imaginativa de nuestra comprensión moral, con sus valores, sus limitaciones y sus oscuridades. Necesitamos un conocimiento similar de otras personas, tanto de los que comparten nuestra tradición cultural como de los que pertenecen a otras tradiciones. Necesitamos imaginar cómo varias acciones nos pueden abrir la posibilidad de alterar nuestra identidad, modificar nuestras convicciones, cambiar nuestras relaciones e influir en la vida de los demás. Necesitamos explorar con la imaginación lo que esto significa de cara a las posibilidades de un sentido y de unas relaciones intensificadas en el caso de hacer una u otra acción. Necesitamos la habilidad de imaginar y de realizar transformaciones en nuestra comprensión moral, en nuestro carácter, y en nuestra conducta. En resumen, nosotros necesitamos una racionalidad imaginativa que sea a la vez intuitiva, crítica, exploratoria y transformadora» ${ }^{16}$.

Si la escuela quiere ser un laboratorio de pensamiento crítico ha de configurarse como una comunidad de diálogo, en donde las opiniones y creencias de cada uno de sus miembros estén abiertas al cuestionamiento propio y ajeno. Las personas que intervienen en un proceso de diálogo parten siempre de unas ideas y juicios previos -prejuicios- y de unas premisas, no siempre explícitas, que delimitan, a su vez, el horizonte de interpretación de las emisiones lingüísticas. Este tipo de saber compartido ha sido interiorizado por el ser humano desde la infancia, junto con las concepciones, creencias, valoraciones, metas y propósitos propios de los grupos sociales a los que pertenece. El pensamiento crítico en sentido fuerte ${ }^{17}$ es aquél que se realiza desde la escucha de otras palabras y de las palabras de los otros, las cuales pueden cuestionar la validez de nuestros prejuicios y de nuestros criterios de valoración, que con frecuencia aceptamos acríticamente, y que podrían no ser sino los que a determinados grupos interesa que tengamos para satisfacer así sus propios y parti-

\footnotetext{
${ }^{16}$ JOHNSON M., Moral imagination, Chicago, The University of Chicago Press, 1993, p. 187.

17 PAUL R, Critical thinking, California, Sonoma State University, 1990. Este autor distingue entre pensamiento crítico débil -o pensamiento diestro- y pensamiento crítico fuerte. El primero es el que utiliza criterios de racionalidad para elegir los medios que hay que emplear para conseguir los fines que se nos proponen, mientras que el segundo es aquél que también somete a consideración crítica los propios fines desde los megacriterios de la verosimilitud, la bondad, la justicia, la corrección o la belleza.
} 
culares intereses. La comunidad educativa ha de hacer presente las voces de los otros, de los marginados, de los excluidos y víctimas del sistema, de los niños, porque sólo sus voces o sus silencios pueden ayudarnos a cuestionar nuestras propias seguridades y las falsedades en que se asientan muchas de nuestras creencias. Sólo el discurso del otro, sobre todo del que puede sufrir las consecuencias negativas de mis opiniones, es capaz de cuestionar los prejuicios desde los que inevitablemente pienso.

Para pensar la complejidad hay que apostar por una racionalidad dialógica, que es la que nos permite resistir ante las pretensiones del discurso único, el cual trata de imponer la norma y la lógica del poder -racionalidad monológica-. Sólo así la razón podrá ser liberadora, y para ello tendrá que posibilitar la heteroglosia, es decir, la confluencia y el encuentro con las palabras de los demás, creando un espacio en donde estas voces no se anulen mutuamente sino que, como en la polifonía, se mantengan entrelazadas en un proceso dialógico, es decir, en un diálogo en el que no se anula el conflicto y en donde no se pretende reducir la diversidad de opiniones a un único punto de vista. La razón dialógica es poliglósica, pues desafía las pretensiones de exclusividad de un lenguaje único, autoritario, que suprime al otro y da validez sólo a un determinado punto de vista. Como señala M. Bajtin, la dialogía no pretende, como el diálogo dialéctico, reducir los diferentes discursos enfrentados a uno solo que cosifique el objeto del conocimiento, y en el que desaparezca la diversidad de entonaciones y matices: mientras la dialéctica trata de definir los límites de la identidad, convertida en objeto, la dialogía permite al Yo reconocerse en el Otro $^{18}$. Pero este Otro, a su vez, me cuestiona e interpela exigiéndome una respuesta -responsabilidad- de carácter ético. Una racionalidad crítica está abierta a este cuestionamiento, como dice E. Levinas: «La crítica no reduce lo otro al mismo como la ontología, sino que cuestiona el ejercicio del mismo. Un cuestionamiento al mismo -que no puede hacerse en la espontaneidad egoísta del mismo- se efectúa por el otro. A este cuestionamiento de mi espontaneidad se llama ética ${ }^{19}$. La dialogía de Bajtin no es sólo una forma de leer o un método de crítica literaria, sino una forma de comprender el mundo y de transformarlo, y así lo entiende Iris M. Zavala, una de las máximas autoridades en el pensamiento de Bajtin y su círculo: «Sugiero que la dialogía es una forma

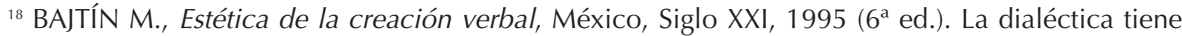
que ver con la identidad abstracta cosificadora: «Diálogo y dialéctica. En el diálogo se hacen desaparecer las voces (separación entre las voces), se eliminan las entonaciones (emocionales y personales), de las palabras vivas y de las réplicas se extraen nociones y juicios abstractos, todo se introduce en una sola conciencia abstracta, y el resultado es la dialéctica» (p. 369 y s.). La dialogía, en cambio, nos permite abrirnos al sentido completo de los otros sujetos discursivos: «Acerca del problema de las relaciones dialógicas. Estas relaciones son muy particulares y no pueden ser reducidas ni a las relaciones lógicas, ni a las del sistema de la lengua, ni a las psicológicas, ni a las mecánicas, ni a cualquier otro tipo de relaciones naturales. Es una clase específica de relaciones entre sentidos, cuyos participantes pueden ser únicamente enunciados completos (o enunciados vistos como completos, o enunciados potencialmente completos), detrás de los cuales están (y en algunos casos se expresan) los sujetos discursivos reales o potenciales, autores de estos enunciados» (p. 316). Para estudiar la importancia que tiene en la ética y estética de Bajtín la categoría de la Alteridad, puede verse el interesantísimo libro de PONZIO A., La revolución bajtiana. El pensamiento de Bajtín y la ideología contemporánea, Madrid, Cátedra, 1998.
}

${ }^{19}$ LEVINAS E., op. cit. p. 67. 
cognoscitiva integradora que interroga la violencia, las totalizaciones, los autoritarismos, las verdades únicas en argumentos literarios, teóricos o filosóficos. No rompe simplemente con las interpretaciones tradicionales y canónicas, sino que las altera totalmente. Intenta replantear la manera en que los individuos o colectividades representan las palabras, utilizan su forma y su sentido, componen sus discursos, muestran y ocultan en ellos lo que piensan, dicen o no dicen, y en todo ello dejan una cantidad de huellas verbales -voces- que es necesario descifrar y restituir en la medida de lo posible. En suma, la práctica dialógica involucra una intervención, una respuesta del lector que supone una transformación activa del mundo $»^{20}$. Para pensar la complejidad es necesario, pues, disponer de una red entretejida con los filamentos de los discursos de todos los que tienen algo fundamentado que decir (com-plexa), y cuantas más hebras tenga la red, cuantos más puntos de vista sean recogidos, mejor podremos pensar la realidad.

Si la comunidad educativa quiere ser realmente liberadora y transformadora ha de comprometerse con el cultivo de la razonabilidad. Ha de ser el espacio en donde sea posible una razón dialógica, en donde surja un pensamiento crítico capaz de cuestionar las pretensiones de verdad, universalidad y unicidad de los discursos monológicos. Ha de ser una comunidad en donde los participantes, mediante el diálogo, construyan interpretaciones de la realidad y las experimenten creando espacios en los que quepa la pluralidad y en donde sea posible, al mismo tiempo, la justicia.

Entiendo el filosofar como el ejercicio de un tipo de racionalidad que nos permita pensar la complejidad, para lo cual ha de facilitar el diálogo entre las diferentes disciplinas que tienen como objetivo entender la realidad, y ha de integrar los distintos puntos de vista desde los que ésta es interpretada. El pensamiento filosófico se ejercita en las fronteras que artificialmente se establecen entre los distintos sistemas de conocimiento y tiene como misión ensanchar los límites de éstos y ampliar, de este modo, nuestro horizonte de comprensión. La misión de la filosofía es la de urgir y viabilizar un pensamiento complejo, en un proceso que no tiene final, ya que la realidad cambia constantemente ${ }^{21}$. La tarea filosófica consiste en posibilitar una manera de mirar y contemplar la realidad que nos permita una comprensión profunda de la misma (theoría) y nos descubra también todas las posibilidades de transformación que ella encierra. Sólo un pensamiento de este tipo será capaz de orientar una acción (praxis) liberadora de las cadenas que nos mantienen a los prisioneros actuales amarrados ante las sombras. La filosofía ha de tejer con el mayor número posible de filamentos la red que debemos utilizar para intentar comprender la realidad

\footnotetext{
${ }^{20}$ ZAVALA I. M., La posmodernidad y Mijail Bajtin, Madrid, Espasa Calpe, 1991, p. 22.

${ }^{21}$ El programa de Filosofía para Niños es un proyecto educativo que pretende fomentar el desarrollo del pensamiento complejo mediante el diálogo filosófico realizado en comunidades de investigación desde el nivel de la educación infantil. Su autor, M. LIPMAN (Pensamiento complejo y educación, Madrid, Ed. de la Torre,1997) entiende que el pensamiento complejo incluye tanto el pensamiento crítico fuerte, como el pensamiento creativo y el pensamiento cuidadoso (caring thinking). Ediciones De la Torre ha publicado el currículo completo -novelas y manuales de investigación- de que consta el programa de Filosofía para Niños, así como algunos otros libros de carácter más bien teórico relacionados con el mismo.
} 
en su integridad, una realidad que es polimórfica y que no puede ser entendida si sólo se la mira desde una única perspectiva. La filosofía es la voz que continuamente nos despierta del sueño placentero que nos invade cuando creemos dogmáticamente que ya hemos llegado al final del camino, recordándonos que siempre cabe otra forma de pensar y que siempre podemos ensayar otras formas de relacionarnos, porque el que tenemos no es nunca el único mundo posible. Si la filosofía es el esfuerzo por construir una racionalidad pragma-dialógica capaz de pensar la complejidad, su didáctica, es decir, el modo de su realización concreta, ha de ser también el pragma-dialógico: diálogo reflexivo que surge desde y para la acción. La clase de filosofía debe ser un laboratorio de racionalidad entendida en este sentido, en el cual se intenta construir una comunidad que mediante el diálogo se dedica a reflexionar sobre los grandes problemas que nos afectan a los seres humanos, aquellos que nos son comunes por nuestra condición de tales, es decir, que más nos importan (inter-esse).

La filosofía ha de ser la garante de una racionalidad corporeizada, encarnada en los sentimientos y en las experiencias que los seres humanos adquieren en su relación con el mundo, cuyos procesos y productos son siempre provisionales, pues tienen que ver con la vaguedad, con los procesos comunicativos, que son siempre históricos y están mediados siempre por circunstancias biográficas y culturales. Se trata de una razonabilidad probatoria, que camina a tientas y cuyos logros son siempre susceptibles de ser revisados. Pero esta revisión no se puede hacer sino desde la misma razón compartida, es decir, desde la razón dialógica. El olvido de una razón de este tipo y la dogmática pretensión de ser el único portador de la «auténtica» razón monológica, la cual ha de ser impuesta por la fuerza, es la causa de la actual misología, que tanto daño y sufrimiento está produciendo en nuestros días, especialmente en las víctimas de un sistema económico que niega la posibilidad de vivir con la dignidad que les corresponde a la mayor parte de la población de este planeta, y en una gran cantidad de hombres y mujeres que son víctimas de guerras, de torturas y del terror que otros seres humanos producen. 